\title{
Update on Renal Function Assessment
}

\author{
Destefani AC* and Taufner GH \\ Department of Biotechnology, Federal University of Espírito Santo (UFES), Brazil
}

Submission: April 17, 2017; Published: June 05, 2017

*Corresponding author: Destefani AC, Department of Biotechnology, Federal University of Espírito Santo (UFES), Brazil, Email: afraniocd@gmail.com

\begin{abstract}
Patients with kidney disease may have an assortment of various clinical appearances. Some have indications that are straightforwardly referenced to the kidney (naturally visible hematuria, flank agony) or additional renal (edema, hypertension, indications of uremia). Numerous patients, in any case, are asymptomatic and are distinguished by routine examinations since they show a high serum creatinine focus or an unusual pee test. When kidney disease is found, the nearness or level of renal brokenness and the speed of movement are evaluated, and the basic issue is analyzed. Albeit past history and physical examination are helpful, the most important data is at first acquired from the estimation of the glomerular filtration rate (GFR) and the examination of the urinary dregs. The gauge of GFR is utilized clinically to evaluate the level of renal debilitation and the course of the disease. In any case, the glomerular filtration rate does not give data on the reason for kidney disease. This is accomplished through urinalysis (estimation of urinary protein discharge) and, if important, radiological reviews and/or renal biopsy. This article intends to give a review of inquiries in regards to the appraisal of GFR in patients with interminable kidney disease.
\end{abstract}

Keywords: Renal function, Glomerular filtration rate, Assessment of GFR

\section{Current Overview of the Renal Function}

Before examining the assessment of renal capacity, it is valuable to quickly audit typical renal physiology. The kidney plays out various basic procedures. It takes part in the support of the consistent extracellular environment that is required for sufficient working of the cells. This is accomplished by discharge of a portion of the waste results of digestion system, (for example, urea, creatinine, and uric acid) and by particularly modifying the urinary discharge of water and electrolytes to match net admission and endogenous generation. The kidney can control separately the discharge of water and solutes, for example, sodium, potassium, and hydrogen, to a great extent by changes in tubular reabsorption or emission. It secretes hormones that take an interest in the control of systemic and renal hemodynamics (renin, prostaglandins, and bradykinin), red platelet creation (erythropoietin), and calcium, phosphorus, and bone digestion system (1,25-dihydroxyvitamin D3 or calcitriol).

\section{Glomerular Filtration Rate}

The glomerular filtration rate (GFR) is equivalent to the total of the filtration rates in the greater part of the working nephrons; in this way, the GFR gives a harsh measure of the quantity of working nephrons. The sifting units of the kidney, the glomeruli, channel around 180 liters for each day $(125 \mathrm{ml} /$ min) of plasma. The typical esteem for GFR relies on age, sex, and body measure, and is around 130 and $120 \mathrm{~mL} / \mathrm{min} / 1.73 \mathrm{~m} 2$ for men and ladies, separately, with significant variety even among ordinary people [1].

A relationship amongst age and diminishing GFR has been recommended by a few reviews [2-4]. In the Baltimore Longitudinal review, 254 ordinary people (without renal malady or hypertension and not taking diuretics) were taken after between the years 1958 and 1981 with serial creatinine clearances as a way to appraise GFR [4]. The mean rate of decrease in creatinine leeway was observed to be $0.75 \mathrm{ml} / \mathrm{min}$ every year, and was more noteworthy in patients with hypertension. A fall in GFR was not seeing in roughly $33 \%$ of people. Using GFR evaluated by the altered Modification of Diet in Renal Disease (MDRD) think about condition among members in the NHANES III review, 38 percent of people age 70 years or more seasoned without hypertension or diabetes had assessed GFRs of under $60 \mathrm{ml} / \mathrm{min}$ per $1.73 \mathrm{~m} 2$ [2]. By correlation, such low values were seen in just 0.7 percent of such members between the ages of 20 to 39 years. One examine from Japan computed the creatinine freedom utilizing the Cockcroft-Gault strategy among about 100,000 subjects more seasoned than 20 years old who took an interest in a mass screening [5]. More than 80 percent of those more established than 70 years old had a computed leeway of under $60 \mathrm{ml} / \mathrm{min}$. Notwithstanding, this astoundingly high 
pervasiveness in the exceptionally old might be a relic of how unequivocally age impacts the Cockcroft-Gault condition.

\section{Significance of a declining GFR}

In patients with kidney disease, a lessening in GFR infers either movement of the basic illness or the improvement of a superimposed and regularly reversible issue, for example, diminished renal perfusion because of volume consumption. What's more, the level of GFR has prognostic ramifications in patients with ceaseless kidney ailment, and such patients are arranged, to some degree, as indicated by GFR.

Be that as it may, there is not a correct relationship between's the loss of kidney mass (i.e., nephron misfortune) and the loss of GFR. The kidney adjusts to the loss of a few nephrons by compensatory hyper filtration or potentially expanding solute and water reabsorption in the staying, ordinary nephrons [6-8]. Along these lines, a person who has lost one-portion of aggregate kidney mass won't really have one-a large portion of the typical measure of GFR.

These ideas have vital outcomes. A stable GFR does not really suggest stable ailment. Indications of illness movement other than a change in GFR must be examined, including expanded action of the pee residue, an ascent in protein discharge, or a rise in circulatory strain. Similarly, an expansion in GFR may demonstrate change in the kidney disease or may infer a counterproductive increment in filtration (hyper filtration) because of hemodynamic variables. Some patients who have genuine basic renal disease may go unrecognized in light of the fact that they have a typical GFR.

\section{Assessment of GFR}

Estimation of glomerular filtration rate (GFR) is perplexing, tedious, and bulky to do in clinical practice. Moreover, correct learning of the GFR is not required for most clinical settings. For instance, realizing that the GFR is $40 \mathrm{ml} / \mathrm{min}$ per $1.73 \mathrm{~m}^{2}$ as opposed to 30 or $50 \mathrm{ml} / \mathrm{min}$ per $1.73 \mathrm{~m}^{2}$ more often than not gives minimal helpful data. What is essential to know is whether the GFR (and in this manner infection seriousness) is changing or is steady. This can normally be controlled by observing the adjustment in serum creatinine or evaluated GFR in many patients with a moderately consistent body mass and eating routine $[9,10]$. In that capacity, GFR is generally assessed from serum markers. In any case, it is every so often essential to have more exact learning of the GFR. Clinical circumstances in which this is the situation include: dosage change of pharmaceuticals, particularly harmful medicines with thin restorative records, for example, chemotherapy; preceding kidney gift; and before deciding the requirement for preemptive transplant. In such conditions, it is sensible to consider measuring GFR.

\section{Typical Qualities}

In the Third National Health and Nutrition Examination Survey in the United States, the mean serum creatinine values for men and ladies were 1.13 and $0.93 \mathrm{mg} / \mathrm{dl}$ (100 and $82 \mu \mathrm{l} / \mathrm{l}$ ), separately [11]. The mean values additionally shifted by race. For non-Hispanic blacks, the mean serum creatinine was $1.25 \mathrm{mg} / \mathrm{dl}$ in men and $1.01 \mathrm{mg} / \mathrm{dl}$ in ladies. The qualities were lower in non-Hispanic whites $11.16 \mathrm{mg} / \mathrm{dl}$ in men and $0.97 \mathrm{mg} /$ $\mathrm{dl}$ in ladies) and in Mexican-Americans $(1.07 \mathrm{mg} / \mathrm{dl}$ in men and $0.86 \mathrm{mg} / \mathrm{dl}$ in ladies). The mean qualities will all be lower with the reception of more current creatinine measures traceable to reference materials.

\section{Necessity for Stable Kidney Work}

Serum creatinine must be utilized to gauge GFR in people with stable kidney work [12]. Ahead of schedule over the span of intense kidney damage, for instance, the GFR is especially decreased yet there has not yet been the ideal opportunity for creatinine to amass and, along these lines, for the serum creatinine to mirror the level of renal brokenness. With stable kidney work, as found in patients with ordinary kidney work or perpetual kidney infection, an ascent in serum creatinine quite often speaks to a decrease in GFR. Notwithstanding, certain medications can meddle with either creatinine discharge or the test used to gauge the serum creatinine, and dietary changes or dietary supplements can modify creatinine generation. In these settings, there will be no change in GFR and no simultaneous rise in the blood urea nitrogen (BUN).

\section{Variety in Creatinine Generation}

The generation of creatinine contrasts among and inside individuals after some time. As cases, people with critical varieties in dietary admission (veggie lover consume less calories, creatine supplements) or decrease in bulk (removal, unhealthiness, muscle squandering) deliver distinctive measures of creatinine than the all inclusive community. The exactness of estimation conditions is influenced to a more prominent degree among lower furthest point amputees, given the much more noteworthy diminishment in bulk, contrasted and furthest point removals. There are sure settings in which there might be an intense increment in creatinine stack. One illustration is a late meat supper. Also, it has been proposed that the serum creatinine rises all the more quickly with rhabdomyolysis (up to $2.5 \mathrm{mg} / \mathrm{dl}$ or $220 \mathrm{micromol} / \mathrm{l} /$ day) than with different reasons for intense kidney damage [13]. Arrival of preformed creatinine from harmed muscle or potentially arrival of creatine phosphate that is then changed over into creatinine in the extracellular liquid has been proposed as clarifications for this finding. Be that as it may, neither of these systems seems to represent the greater part of the expansion in the serum creatinine fixation [14]. An option clarification is that rhabdomyolysis regularly influences generally sound men with a high bulk and a higher rate of creatinine generation while different types of intense kidney damage every now and again influence patients who are incessantly sick [14].

\section{Variety in Creatinine Excretion}

The exactness of GFR estimation with both the creatinine freedom and creatinine-based estimation conditions is 
constrained by the way that as the GFR falls, the ascent in the serum creatinine is incompletely contradicted by improved proximal tubular creatinine discharge [6,7,15-17]. In early renal illness when the GFR is still close ordinary, an underlying decrease in GFR may prompt to just a slight increment $(0.1$ to $0.2 \mathrm{mg} / \mathrm{dl}$ [ 9 to $18 \mathrm{micromol} / \mathrm{L}$ ]) in the serum creatinine. The net impact is that patients with a genuine GFR as low as 60 to $80 \mathrm{ml} / \mathrm{min}$ (as measured by the freedom of a genuine filtration marker, for example, inulin or radioisotopiciothalamate or DTPA $[15,18]$ may at present have a serum creatinine that is $\leq 1 \mathrm{mg}$ / dl (88 micromol/l) [19]. In this way, a generally stable serum creatinine in the typical or close ordinary range does not really suggest that the sickness is steady. In any case, once the serum creatinine surpasses 1.5 to $2 \mathrm{mg} / \mathrm{dl}$ (132 to $176 \mathrm{micromol} / \mathrm{L}$ ), the secretory procedure is successfully saturated. After this, a steady esteem normally speaks to a stable GFR [20].

\section{The Accompanying Clinical Cases are Illustrative}

A man with unrecognized renal illness and an underlying serum creatinine of $0.9 \mathrm{mg} / \mathrm{dl}(79.6 \mathrm{micromol} / \mathrm{L})$ has a decrease in his actual GFR from 120 to $70 \mathrm{ml} / \mathrm{min}$ per $1.73 \mathrm{~m}^{2}$ (loss of $50 \mathrm{ml} / \mathrm{min}$ per $1.73 \mathrm{~m}^{2}$, or around 40 percent of his GFR). Utilizing the theoretical relationship amongst GFR and creatinine (which overlooks creatinine emission), the serum creatinine increased by GFR is a consistent, and the serum creatinine would be relied upon to ascend to around $1.7 \mathrm{mg} / \mathrm{dl}$ (150.3micromol/L) (Figure 1). Nonetheless, his real ascent in serum creatinine is much littler, to $1.2 \mathrm{mg} / \mathrm{dl}$ (106.1 micromol/L), on account of expanded creatinine discharge. In spite of the fact that a serum creatinine of $1.2 \mathrm{mg} / \mathrm{dl}$ is in the ordinary range, this ought not to be erroneously thought to be typical or characteristic of just mellow illness. The seriousness of the GFR decrease was not evident because of an expansion in creatinine discharge. Early identification of dynamic kidney ailment is especially vital as a result of the accessibility of treatments, especially pulse bringing down with angiotensin-changing over catalyst inhibitors, which can moderate the rate of movement in numerous patients. In another patient with more propelled infection, the serum creatinine is $4 \mathrm{mg} / \mathrm{dl}$ (354micromol/l) and the GFR $15 \mathrm{ml} / \mathrm{min}$. Since creatinine discharge is saturated, an ascent in serum creatinine (SCr) to $6 \mathrm{mg} / \mathrm{dl}$ (530micromol/L) mirrors a GFR of $10 \mathrm{ml} / \mathrm{min}$ or lost just $5 \mathrm{ml} / \mathrm{min}$ [21].

What's more, creatinine emission might be improved or restrained in certain clinical circumstances. As illustrations tubular creatinine discharge is altogether expanded in patients with the nephrotic disorder. In one review, in which GFR was dictated by inulin leeway, diminished serum egg whites levels were connected with a checked increment in tubular creatinine discharge $\left(36 \mathrm{ml} / \mathrm{min}\right.$ per $1.73 \mathrm{~m}^{2}$ for nephrotic patients with serum egg whites levels under $2.6 \mathrm{~g} / \mathrm{dl}$ versus $11 \mathrm{ml} / \mathrm{min}$ per $1.73 \mathrm{~m}^{2}$ for ordinary controls) [22]. Patients with sickle cell infection may likewise have an expansion in creatinine discharge. Hence, patients with nephrotic disorder and sickle cell ailment may have a GFR that is considerably lower than what can be accessed from the serum creatinine. The level of creatinine emission may differ with time, influencing the serum creatinine autonomous of the GFR [23]. In successfully treated lupus nephritis, for instance, an ascent in the GFR may not be joined by the normal diminishment in the serum creatinine because of a fall (through an indeterminate instrument) in creatinine emission. In this setting, diminished movement of the pee silt, lessened protein discharge, and absence of further height in the serum creatinine all indicate conceivable change. The nearness of specific medications may build the level of the serum creatinine by diminishing creatinine emission. These medications incorporate trimethoprim (which is regularly given in blend with sulfamethoxazole) and the H2-blocker cimetidine, which result in a self-constrained and reversible ascent in the serum creatinine of as much as 0.4 to $0.5 \mathrm{mg} / \mathrm{dl}$ (35 to $44 \mathrm{micromol} / \mathrm{l}$ ).

\section{Extrarenal Creatinine Discharge}

Extrarenal creatinine disposal is expanded in cutting edge kidney disappointment (e.g., assessed GFR $<15 \mathrm{~mL} / \mathrm{min}$ per $1.73 \mathrm{~m}^{2}$ ). In this setting, there is intestinal bacterial abundance and expanded bacterial creatininase action [24]. Thus, the serum creatinine focus is lower than would be normal from the GFR.

\section{Estimation Issues}

Serum creatinine is frequently measured by the antacid picrate strategy. Certain substances may meddle with the examiner, in this way artifactually expanding the serum creatinine focus. This colorimetric test can perceive different mixes as creatinine chromogens, especially acetoacetate in diabetic ketoacidosis [25-27]. In this setting, the serum creatinine can ascend by 0.5 to $>2 \mathrm{mg} / \mathrm{dl}$ ( 44 to $176 \mathrm{micromol} / \mathrm{L}$ ), a change that is quickly turned around with inulin treatment. Cefoxitin and flucytosine are medications that can create a comparable impact.

Contrasts in strategy and gear can prompt to variety in revealed serum creatinine values (irregular estimation blunder) [28]. In a review assessing more than 5000 research facilities utilizing 20 distinct instruments to gauge serum creatinine by up to three unique strategies (basic picrate and enzymatic), the mean serum creatinine fixation on an institutionalized example went from 0.84 to $1.21 \mathrm{mg} / \mathrm{dL}$ ( 74.3 to $107 \mathrm{micromol} / \mathrm{l}$ ) [29]. Predisposition identified with instrument producer was more prominent than that because of strategy. This variety has been generously diminished by the national program set up by the National Kidney Disease Education Program (NKDEP) to institutionalize creatinine examines with the goal that they are all traceable to reference materials. Most producers now utilize such calibrators and in this way most clinical research facilities in the United States have examines traceable to these reference materials.

The variety in serum creatinine estimation techniques prompts to variety in creatinine-based GFR estimation. This was appeared in a review that analyzed solidified examples from 
212 and 342 MDRD and NHANES III members, individually [30]. Creatinine was measured in MDRD and NHANES III with various examines. At the point when creatinine was measured on a similar blood tests utilizing both examine, the serum creatinine was all things considered $0.23 \mathrm{mg} / \mathrm{dl}$ (20.3micromol/l) higher with the NHANES III test. This distinction can bring about generous varieties in GFR estimation when the serum creatinine focus is generally ordinary. This information likewise propose that adjustments in serum creatinine of $\pm 0.3 \mathrm{mg} / \mathrm{dl}$ (26micromol/l) measured in various research centers may speak to varieties in the test as opposed to varieties in GFR; the variety is much littler in rehashed estimations in a similar lab. The acknowledgment that varieties in serum creatinine estimations can substantially affect the appraisal of kidney capacity has prompted to progressing endeavors to institutionalize creatinine estimations crosswise over research centers [1].

\section{Conclusion}

The typical esteem for glomerular filtration rate (GFR) relies on age, sex, and body estimate, and is roughly 130 and 120ml/ $\min / 1.73 \mathrm{~m}^{2}$ for men and ladies, separately, with extensive variety even among ordinary people. GFR every now and again diminishes with age. In patients with kidney ailment, a lessening in GFR suggests either movement of the fundamental infection or the advancement of a superimposed and frequently reversible issue. Furthermore, the level of GFR has prognostic ramifications in patients with ceaseless kidney malady, and such patients are organized, partially, as per GFR. Notwithstanding, there is not a correct relationship between's the loss of kidney mass (i.e., nephron misfortune) and the loss of GFR. The kidney adjusts to the loss of a few nephrons by compensatory hyper filtration as well as expanding solute and water reabsorption in the staying, typical nephrons. Estimation of GFR is minded boggling, tedious, and bulky to do in clinical practice. What's more, correct learning of the GFR is not required for most clinical settings. Accordingly, GFR is generally evaluated from serum markers. Nonetheless, it is every so often vital to have more exact learning of the GFR (e.g., preceding kidney gift). GFR is measured by deciding the urinary leeway of a perfect filtration marker. Inulin is the highest quality level filtration marker, yet iothalamate and iohexol are less bulky. The most widely recognized strategies used to evaluate the GFR are: estimation of the creatinine freedom; and estimation conditions based upon serum creatinine, for example, the Cockcroft-Gault condition, the Modification of Diet in Renal Disease (MDRD) ponders conditions, and the Chronic Kidney Disease Epidemiology Collaboration (CKD-EPI) condition. GFRevaluating conditions utilized as a part of practice depend upon creatinine as a marker of kidney capacity. Serum creatinine must be utilized to assess GFR in people with stable kidney work. Furthermore, creatinine-based estimations of the GFR are constrained by varieties in creatinine generation, varieties in creatinine discharge, extra renal creatinine discharge, and issues connected with creatinine estimation. Estimation of the creatinine leeway can be utilized to affirm evaluated GFR from serum creatinine when there are varieties in creatinine generation. Measured creatinine freedom is constrained by blunders in pee accumulation, and also creatinine emission, extra renal creatinine discharge, and issues connected with creatinine estimation. Creatinine is unreservedly sifted over the glomerulus and is neither reabsorbed nor metabolized by the kidney. Be that as it may, around 10 to 40 percent of urinary creatinine is gotten from tubular discharge by the natural cation secretory pathways in the proximal tubule. On the off chance that the impact of discharge is overlooked, then the creatinine leeway will be equivalent to the GFR. Be that as it may, the creatinine leeway has a tendency to surpass the genuine GFR by around 10 to 20 percent or more since this is the part of urinary creatinine that is gotten from tubular emission. Likewise, utilizing the creatinine freedom to appraise GFR is constrained by mistakes in pee gathering and variety in the level of creatinine discharge, which increments as GFR declines. The most widely recognized conditions utilized as a part of the United States are the Cockcroft-Gault and the Modification of Diet in Renal Disease (MDRD) think about conditions. The CKD-EPI condition is more accurate than the MDRD think about condition. The MDRD and CKD-EPI conditions are standardized to body surface zone. The MDRD think about condition is the most normally utilized estimation condition, and has been re-communicated for use with creatinine values that are institutionalized to creatinine reference materials measured utilizing best quality level strategies (Gold standard MDRD examine condition). The CKD-EPI condition was produced to give a more accurate gauge of GFR among people with ordinary or just somewhat diminished GFR (i.e., over $60 \mathrm{ml} / \mathrm{min}$ per $1.73 \mathrm{~m}^{2}$ ). Among patients with GFRs more prominent than $60 \mathrm{ml} / \mathrm{min}$ per $1.73 \mathrm{~m} 2$, the CKD-EPI condition was connected with less inclination, enhanced exactness, and more noteworthy precision. The CKD-EPI condition brings about a lower pervasiveness gauge of CKD and more accurate hazard expectation for antagonistic results contrasted and the MDRD consider condition. Given the information on the enhanced execution, particularly at more elevated amounts of GFR, we recommend utilizing the CKD-EPI condition for the all inclusive community. Notwithstanding the issues connected with dependence upon serum creatinine, the generally used estimation conditions are less accurate in specific populaces. These incorporate people with typical GFR, kids, elderly patients, particular ethnic gatherings (e.g., Asians in the United States), pregnant ladies, and those with irregular bulk, body habitus, and weight (e.g., bleak corpulence, amputees). On the off chance that the MDRD assessed GFR is utilized for medication dosing in extensive or little patients, the revealed evaluated GFR (which is standardized to body surface territory) ought to be increased by the assessed body surface region, and afterward isolated by 1.73 , to acquire an expected GFR in units of $\mathrm{ml} / \mathrm{min}$ (i.e., not standardized to body surface zone). For patients at the extremes of bulk, with irregular weight control 
plans, or with conditions connected with changes in creatinine discharge, all estimation conditions that utilization the serum creatinine are constrained; in this way, a deliberate creatinine freedom or GFR utilizing exogenous filtration markers ought to be performed particularly when recommending drugs with a thin helpful window. The estimation of the freedom of urea is helpful in one setting. Among patients with extreme kidney malady (e.g., a serum creatinine more noteworthy than $2.5 \mathrm{mg} / \mathrm{dl}$ [220micromol/1]), the urea leeway altogether thinks little of the GFR. Since the creatinine leeway altogether overestimates this capacity, one strategy to assess the GFR in patients with cutting edge renal sickness is to normal both the creatinine and urea clearances. Cystatin C in mix with creatinine is more accurate for the appraisal of GFR than serum creatinine in specific populaces and can be utilized as a corroborative test for determination of CKD and for estimation of GFR.

\section{References}

1. Stevens LA, Coresh J, Greene T, Levey AS (2006) Assessing kidney function--measured and estimated glomerular filtration rate. $\mathrm{N}$ Engl J Med 354(23): 2473-2483.

2. Coresh J, Astor BC, Greene T, Eknoyan G, Levey AS (2003) Prevalence of chronic kidney disease and decreased kidney function in the adult US population: Third National Health and Nutrition Examination Survey. Am J Kidney Dis Off J Natl Kidney Found 41(1): 1-12.

3. Zhou XJ, Rakheja D, Yu X, Saxena R, Vaziri ND, et al. (2008) The aging kidney. Kidney Int 74(6): 710-720.

4. Lindeman RD, Tobin JD, Shock NW (1984) Association between blood pressure and the rate of decline in renal function with age. Kidney Int 26(6): 861-868.

5. Iseki K, Kinjo K, Iseki C, Takishita S (2004) Relationship between predicted creatinine clearance and proteinuria and the risk of developing ESRD in Okinawa, Japan. Am J Kidney Dis 44(5): 806-814.

6. van Acker BAC, Koopman MG, Arisz L, Koomen GCM, de Waart DR (1992) Creatinine clearance during cimetidine administration for measurement of glomerular filtration rate. Lancet 340(8831): 13261329.

7. Petri M, Bockenstedt L, Colman J, Whiting-O’Keefe Q, Fitz G, et al. (1988) Serial assessment of glomerular filtration rate in lupus nephropathy. Kidney Int 34(6): 832-839.

8. Chagnac A, Kiberd BA, Farinas C, Strober S, Sibley RK, et al. (1989) Outcome of the acute glomerular injury in proliferative lupus nephritis. J Clin Invest 84: 922-930.

9. Rodrigo E, de Francisco ALM, Escallada R, Ruiz JC, Fresnedo GF, et al (2002) Measurement of renal function in pre-ESRD patients. Kidney Int Suppl 61(80): 11-17.

10. Traynor J, Mactier R, Geddes CC, Fox JG (2006) How to measure renal function in clinical practice. BMJ 333(7571): 733-737.

11. Jones CA, McQuillan GM, Kusek JW, Eberhardt MS, Herman WH, et al. (1998) Serum creatinine levels in the US population: third National Health and Nutrition Examination Survey. Am J Kidney Dis Off J Natl Kidney Found 32(6): 992-999.

12. Rule AD, Bergstralh EJ, Slezak JM, Bergert J, Larson TS (2006) Glomerular filtration rate estimated by cystatin $\mathrm{C}$ among different clinical presentations. Kidney Int 69(2): 399-405.
13. Bosch X, Poch E, Grau JM (2009) Rhabdomyolysis and acute kidney injury. N Engl J Med 361: 62-72.

14. Zager RA (1996) Rhabdomyolysis and myohemoglobinuric acute renal failure. Kidney Int 49(2): 314-326.

15. Bostom AG, Kronenberg F, Ritz E (2002) Predictive performance of renal function equations for patients with chronic kidney disease and normal serum creatinine levels. J Am Soc Nephrol 13(8): 2140-2144.

16. Chen S (2013) Retooling the creatinine clearance equation to estimate kinetic GFR when the plasma creatinine is changing acutely. J Am Soc Nephrol 24(6): 877-888.

17. Kim KE, Onesti G, Ramirez O, Brest AN, Swartz C (1969) Creatinine clearance in renal disease. A reappraisal. Br Med J 4(5674): 11-14.

18. Moonen M, Granerus G (1992) Subtraction of extra-renal background in 99mTc-DTPA renography: comparison of various regions of interest. Clin Physiol 12(4): 453-461.

19. Hoste EAJ, Damen J, Vanholder RC, Lameire NH, Delanghe JR, et al. (2005) Assessment of renal function in recently admitted critically ill patients with normal serum creatinine. Nephrol Dial Transplant 20(4):747-753.

20. Hojs R, Bevc S, Ekart R, Gorenjak M, Puklavec L (2011) Kidney function estimating equations in patients with chronic kidney disease. Int J Clin Pract 65(4): 458-464.

21. Spanaus KS, Kollerits B, Ritz E, Hersberger M, Kronenberg F, et al. (2010) Serum creatinine, cystatin C, and $\beta$-trace protein in diagnostic staging and predicting progression of primary nondiabetic chronic kidney disease. Clin Chem 56(5): 740-749.

22. Soares AA, Eyff TF, Campani RB, Ritter L, Camargo JL, Silveiro SP (2009) Glomerular filtration rate measurement and prediction equations. Clin Chem Lab Med 47: 1023-1032.

23. Myers BD, Chagnac A, Golbetz H, Newton L, Strober S, Sibley RK. Extent of glomerular injury in active and resolving lupus nephritis: a theoretical analysis. Am J Physiol 260: F717-727.

24. Serafín V, Hernández P, Agüí L, Yáñez-Sedeño P, Pingarrón JM (2013) Electrochemical biosensor for creatinine based on the immobilization of creatininase, creatinase and sarcosine oxidase onto a ferrocene/ horseradish peroxidase/gold nanoparticles/multi-walled carbon nanotubes/Teflon composite electrode. Electrochim Acta 97: 175-183.

25. Itoh S, Kusaka T, Imai T, Isobe K, Onishi S (2000) Effects of bilirubin and its photoisomers on direct bilirubin measurement using bilirubin oxidase. Ann Clin Biochem 37(Pt 4): 452-456.

26. Cobbaert CM, Baadenhuijsen H, Weykamp CW (2009) Prime time for enzymatic creatinine methods in pediatrics. Clin Chem 55(3): 549-558.

27. Andreu Y, Ostra M, Ubide C, Galbán J, De Marcos S, Castillo JR (2002) Study of a fluorometric-enzymatic method for bilirubin based on chemically modified bilirubin-oxidase and multivariate calibration. Talanta 57(2): 343-353.

28. Coresh J, Astor BC, McQuillan G, Kusek J, Greene T, et al. (2002) Calibration and random variation of the serum creatinine assay as critical elements of using equations to estimate glomerular filtration rate. Am J Kidney Dis 39(5): 920-929.

29. Murthy K, Stevens LA, Stark PC, Levey AS (2005) Variation in the serum creatinine assay calibration: A practical application to glomerular filtration rate estimation. Kidney Int 68(4): 1884-1887.

30. Levey AS, Coresh J, Greene T, Stevens LA, Zhang YL, et al. (2006) Using standardized serum creatinine values in the modification of diet in renal disease study equation for estimating glomerular filtration rate. Ann Intern Med 145(4): 247-254. 
(C) Co This work is licensed under Creative

BY DOI: 10.19080/JOJUN.2017.3.555609

\section{Your next submission with Juniper Publishers} will reach you the below assets

- Quality Editorial service

- Swift Peer Review

- Reprints availability

- E-prints Service

- Manuscript Podcast for convenient understanding

- Global attainment for your research

- Manuscript accessibility in different formats

( Pdf, E-pub, Full Text, Audio)

- Unceasing customer service

Track the below URL for one-step submission https://juniperpublishers.com/online-submission.php 